\title{
PERBANDINGAN HASIL BELAJAR SISWA MENGGUNAKAN MEDIA CHEMOPOLY GAME DAN TOURNAMENT QUESTION CARDS
}

\author{
Dui Sherly Viani**1, Amrul Bahar ${ }^{2}$, Elvinawati ${ }^{3}$ \\ Program Studi Pendidikan Kimia Fakultas Keguruan dan Ilmu Pendidikan Universitas Bengkulu \\ ${ }^{1,2,3}$ Program Studi Pendidikan Kimia Jurusan Matematika dan Ilmu Pengetahuan, FKIP, Universitas Bengkulu \\ *11 e-mail: dui.sherly@yahoo.co.id
}

\begin{abstract}
The low learning outcomes of the students is because in the learning process of teacher and student interaction only goes one way. Teachers often use lecture methods so that students tend to only accept what is given. This can make the students' motivation and activeness in following the lesson to be low. Therefore, researchers try to vary the cooperative learning model using Chemopoly Game media and Tournament Question Cards. This is quasi experimental research with population class X MIPA in SMAN 2 Kota Bengkulu and sample is class X MIPA C using media Tournament Question Cards and class X MIPA D using Chemopoly Game media. Data analysis used were mean score, normality test, homogeneity test, and $t$ test. The average posttest grade of experiment I is 85,59 While for experiment class II is 79,38. Then $t$ test and obtained tcount $>$ ttable (2.62> 2.38). The results of this study indicate that there is a significant difference between student learning outcomes using Chemopoly Game media and Tournament Question Cards on basic chemical law materials.
\end{abstract}

Keywords : Chempoly Game, Tournament Question Cards, Learning Outcomes

\begin{abstract}
Abstrak
Rendahnya hasil belajar siswa dikarenakan di dalam proses pembelajaran interaksi guru dan siswa hanya berjalan satu arah. Guru sering menggunakan metode ceramah sehingga siswa cenderung hanya menerima apa yang diberikan. Hal ini dapat membuat motivasi serta keaktifan siswa dalam mengikuti pelajaran menjadi rendah. Oleh sebab itu, peneliti mencoba memvariasikan model pembelajaran kooperatif menggunakan media Chemopoly Game dan Tournament Question Cards. Jenis penelitian yang digunakan adalah penelitian eksperimen dengan populasi kelas X MIPA di SMAN 2 Kota Bengkulu dan sampel adalah kelas X MIPA C yang menggunakan media Tournament Question Cards dan kelas X MIPA D yang menggunakan media Chemopoly Game. Analisa data yang digunakan adalah nilai rata-rata, uji normalitas, uji homogenitas, dan uji t. Nilai rata-rata posttest kelas eksperimen I adalah 85,59, sedangkan untuk kelas eksperimen II adalah 79,38. Kemudian dilakukan uji t dan diperoleh $t_{\text {hitung }}>t_{\text {tabel }}(2,62>2,38)$. Hasil penelitian ini menunjukkan bahwa terdapat perbedaan yang signifikan antara hasil belajar siswa yang menggunakan media Chemopoly Game dan Tournament Question Cards pada materi hukum dasar kimia.
\end{abstract}

Kata kunci : Chemopoly Game, Tournament Question Cards, Hasil Belajar

\section{PENDAHULUAN}

Pendidikan merupakan faktor yang sangat penting dalam menentukan masa depan manusia dan bermanfaat bagi pelaksanaan pembangunan dalam rangka mencapai tujuan nasional. Upaya meningkatkan mutu pendidikan salah satunya adalah pembaharuan proses pembelajaran yang berkualitas dan bersifat menyeluruh sehingga dapat menghasilkan peserta didik yang mampu berperan aktif dalam pembangunan Indonesia dapat tercapai [1]. Mata pelajaran kimia sebagai mata pelajaran wajib bagi siswa SMA IPA diajarkan untuk tujuan khusus yaitu membekali peserta didik pengetahuan, pemahaman dan sejumlah kemampuan yang dipersyaratkan untuk memasuki jenjang pendidikan yang lebih tinggi serta mengembangkan ilmu dan teknologi. Hal ini tidak menutup kemungkinan akan adanya kesulitan bagi siswa dalam mengikuti proses pembelajaran kimia [2]. Bagi siswa SMA N 2 Kota Bengkulu, khususnya pada kelas X MIPA pelajaran kimia merupakan pelajaran yang sulit dan terkadang membosankan.

Dari hasil wawancara dengan guru mata pelajaran kimia di SMAN 2 Kota Bengkulu, diketahui bahwa ratarata hasil ujian tengah semester 1 mata pelajaran kimia kelas X MIPA masih belum mencapai Kriteria Ketuntasan Minimal (KKM) yaitu 75 yang menunjukan bahwa pemahaman konsep kimia yang dimiliki siswa masih rendah, antara lain karena sebagian besar guru masih menggunakan metode konvensional yakni ceramah yang mengakibatkan pembelajaran menjadi membosankan dan siswa jenuh dalam mengikuti pelajaran [3]. Salah satu upaya untuk memperbaiki kualitas proses pembelajaran, yaitu dengan menerapkan model pembelajaran yang dapat meningkatkan motivasi dan minat belajar siswa, salah satunya adalah model pembelajaran kooperatif tipe Student Team Achievement Divisions (STAD) [4], yang dalam penerapannya dapat dikembangkan dengan pemanfaatan berbagai media [5], sehingga dapat membantu 
siswa untuk memahami materi pelajaran dan meningkatkan motivasi belajar siswa [6]. Ada beberapa macam media pembelajaran yang dapat digunakan untuk meningkatkan motivasi dan minat siswa, salah satunya yaitu media Chemopoly Game yang merupakan adopsi permainan monopoli yang diubah sesuai dengan fungsinya sebagai media pembelajaran kimia. Dalam Chemopoly Game siswa akan berusaha agar mampu menjawab pertanyaan yang ada di kartu hak milik konsep materi sehingga motivasi siswa untuk serius mempelajari materi yang diajarkan akan meningkat yang diharapkan hasil belajar siswa pun akan meningkat [7], selain itu akan dapat melatih ketelitian dan kesabaran siswa, dan dapat menumbuhkan rasa ingin tahu terhadap materi yang dikemas dalam media tersebut [8].

Media pembelajaran lain yang dapat digunakan untuk meningkatkan minat siswa dan hasil belajar siswa adalah media Tournament Question Cards [9] yang merupakan media visual yang berupa kertas berukuran 10 X $10 \mathrm{~cm}$. Penerapan media Tournament Question Cards akan mempengaruhi tidak hanya pada aspek kognitif siswa namun juga pada aspek afektif dan psikomotorik siswa, sehingga pembelajaran akan berlangsung lebih menarik, menyenangkan, memberikan pengalaman belajar yang berbeda dan dapat membuat siswa lebih mudah memahami materi [10].

Berdasarkan uraian di atas, penelitian ini bertujuan untuk mengetahui hasil belajar siswa yang menggunakan media Chemopoly Game dan media Tournament Question Cards, serta untuk mengetahui perbedaan hasil belajar siswa yang menggunakan media Chemopoly Game dan Tournament Question Cards di kelas X SMA Negeri 2 Kota Bengkulu.

\section{METODE PENELITIAN}

Penelitian ini merupakan kuasi eksperimen dengan membandingkan hasil belajar ranah kognitif siswa pada materi hukum dasar kimia pada pembelajaran kooperatif tipe STAD menggunakan media Chemopoly Game dan Tournament Question Cards. Variabel bebas yaitu media Chemopoly Game dan Tournament Question Cards, variabel terikat yaitu hasil belajar siswa, dan variabel kontrol yaitu model pembelajaran kooperatif tipe Student Team Achievement Division (STAD).

Target populasi dalam penelitian ini adalah seluruh siswa kelas X MIPA di SMA Negeri 2 Kota Bengkulu tahun ajaran 2016/2017 yang terdiri dari 6 (enam) kelas. Pemilihan kelas sampel dilakukan secara random dan kemudian dilakukan uji homogenitas didapatkan dua kelas yang homogen.

Teknik pengumpulan data pada penelitian ini berupa observasi awal, tes hasil belajar yang terdiri dari pretest dan posttest, dan dokumentasi. Teknik analisis data yang digunakan adalah nilai rata-rata kelas, uji normalitas, dan uji t.

\section{HASIL DAN PEMBAHASAN}

Penelitian ini dilaksanakan pada bulan Februari sampai dengan April 2017 di SMA Negeri 2 Kota Bengkulu. Populasi yang digunakan adalah seluruh siswa-siswi kelas X MIPA SMA Negeri 2 Kota Bengkulu. Pada penelitian ini sampel yang terpilih adalah kelas X MIPA C dan X MIPA D, di mana kelas X MIPA $\mathrm{C}$ sebagai kelas eksperimen I yang menggunakan media Tournament Question Cards dan kelas X MIPA D sebagai kelas eksperimen II yang menggunakan media Chemopoly Game.

Tabel 1. Nilai Rata-Rata Hasil Belajar Siswa

\begin{tabular}{ccc}
\hline Variabel & $\begin{array}{c}\text { Kelas Eksperimen I } \\
\text { (TQC) }\end{array}$ & $\begin{array}{c}\text { Kelas Eksperimen } \\
\text { II (CPQ) }\end{array}$ \\
\hline $\mathrm{N}$ & 36 & 36 \\
$\overline{\text { X Pretest }}$ & 28,24 & 28,72 \\
$\overline{\text { X Postest }}$ & 85,59 & 79,38 \\
$\Delta \mathrm{i}$ & 57,35 & 50,67 \\
$\mathrm{SD}$ & 10,90 & 10,79 \\
$\mathrm{~V}$ & 118,96 & 116,34 \\
\hline
\end{tabular}

Nilai rata-rata hasil belajar siswa pada kedua kelas yaitu kelas eksperimen I yang menggunakan media Tournament Question Cards dan kelas eks-perimen II yang menggunakan media Chemopoly Game memiliki nilai pretest yang masih tergolong rendah dan tidak ada siswa yang mencapai nilai standar KKM yaitu 75 (Tabel 1). Sedangkan untuk nilai rata-rata posttest diketahui bahwa pada kelas eksperimen I yang menggunakan media Tournament Question Cards, siswa yang memperoleh nilai posttest di atas standar KKM berjumlah 34 siswa. Pada kelas ekspeimen II yang menggunakan media Chemopoly Game, siswa yang memperoleh nilai post test di atas standar KKM berjumlah 25 siswa. Meningkatnya hasil belajar siswa pada ranah kog-nitif dilihat dari selisih rata-rata nilai pretest dan postttest. Untuk kelas eksperimen I selisih rata-rata nilai pretest dan posttest yaitu 57,35 dan kelas eks-perimen II sebesar 50,67. Besarnya selisih nilai yang diperoleh, maka besar pula peningkatan hasil belajar siswa yang didapat. Pada kelas eksperimen I yang menggunakan media Tournament Question Cards menunjukkan hasil yang lebih baik diban-dingkan kelas eksperimen II yang menerapkan menggunakan media Chemopoly Game.

Tabel 2. Data Uji Normalitas Hasil Belajar Siswa

\begin{tabular}{ccccc}
\hline No & Nilai & $\begin{array}{c}\text { Kelas Eksperimen I } \\
\text { (TQC) }\end{array}$ & $\begin{array}{c}\text { Kelas Eksperimen } \\
\text { II (CPG) }\end{array}$ \\
\hline 1 & $\mathrm{X}_{\text {Hitung }}^{2}$ & 6,76 & 9,22 \\
2 & $\mathrm{X}_{\text {Tabel }}^{2}$ & & 11,34 & \\
\hline
\end{tabular}


Berdasarkan Tabel 2 di atas terlihat bahwa data kedua kelas eksperimen memiliki nilai $\mathrm{X}_{\text {Hitung }}^{2}<\mathrm{X}^{2}$ Tabel, sehingga dapat diketahui bahwa kedua kelas eksperimen berasal dari populasi yang ber-distribusi normal, yang artinya data yang diperoleh memiliki sebaran yang normal dan bisa mewakili populasi.

Tabel 3. Data Uji Homogenitas

\begin{tabular}{ccc}
\hline No & Nilai & Hasil Perhitungan \\
\hline 1 & $\mathrm{~F}_{\text {Hitung }}$ & 1,02 \\
2 & $\mathrm{~F}_{\text {Tabel }}$ & 7,01 \\
\hline
\end{tabular}

Dari hasil perhitungan $\mathrm{F}_{\text {Hitung }}$ dan $\mathrm{F}_{\text {Tabel }}$ pada Tabel 3 terlihat bahwa nilai $\mathrm{F}_{\text {Hitung }}<\mathrm{F}_{\text {Tabel }}$ maka kedua kelas eksperimen mempunyai varians yang homogen, artinya jika data yang berdistribusi normal diambil secara acak, maka data tersebut tidak mengalami perbedaan kemampuan kognitif.

Tabel 4. Data uji $\mathrm{t}$

\begin{tabular}{ccc}
\hline No & Nilai & Hasil Perhitungan \\
\hline 1 & $\mathrm{t}_{\text {Hitung }}$ & 2,62 \\
2 & $\mathrm{t}_{\text {Tabel }}$ & 2,38 \\
\hline
\end{tabular}

Berdasarkan Tabel 4 di atas diketahui bahwa $\mathrm{t}_{\text {Hitung }}>\mathrm{t}_{\text {Tabel }}(2,62>2,38)$, maka pernyataan $\mathrm{H} 0$ ditolak dan pernyataan $\mathrm{Ha}$ diterima. Dengan demikian terdapat perbedaan yang signifikan antara hasil belajar siswa dengan model pembelajaran kooperatif tipe Student Teams Achievement Division menggunakan media Tournament Question Cards dan media Chemopoly Game pada materi hukum dasar kimia. Berdasarkan penjelasan di atas, penggunaan media Tournament Question Cards dan media Chemopoly Game sebagai media pembelajaran sama-sama dapat meningkatkan hasil belajar siswa. Pada dasarnya penggunaan kedua media ini dapat membantu siswa untuk memahami materi pelajaran. Selain itu kedua media ini termasuk ke dalam media permainan, di mana media permainan yang apabila digunakan sebagai media pembelajaran akan dapat secara langsung merangsang minat siswa serta memberikan suasana belajar baru bagi siswa sehingga siswa lebih termotivasi untuk belajar. Hal ini terlihat dari kemauan siswa yang terlibat secara aktif dalam pembelajaran ketika diterapkan kedua media tersebut serta meningkatnya pengetahuan siswa pada aspek ranah kognitif.
Penerapan media Tournament Question Cards dan media Chemopoly Game sebagai media pembelajaran sama-sama membantu siswa untuk memahami konsep-konsep pada materi yang diajarkan. Akan tetapi, di dalam penelitian ini penggunaan media Tournament Question Cards menunjukan hasil yang lebih baik dibandingkan penggunaan media Chemopoly Game, hal ini dikarenakan kedua media memiliki kelebihan dan kekurangan masing-masing sehingga terdapat perbedaan peningkatan hasil belajar siswa.

Pada kelas eksperimen I yang menggunakan media Tournament Question Cards dalam penerapannya mengharuskan setiap anggota kelompok untuk bertanggung jawab terhadap kartu yang didapat. Pembelajaran dengan menggunakan media Tournament Question Cards ini tidak membutuhkan waktu yang lama sehingga saat berdiskusi setiap kelompok dapat saling bertukar informasi mengenai kartu yang didapat dan dapat menyelesaikan soal-soal yang ada di LKS dengan baik. Selain itu, setiap anggota dalam kelompok saling berpartisipasi dan ikut aktif dalam proses pembelajaran. Dalam proses pembelajarannya penggunaan media Tournament Question Cards memiliki kelebihan yaitu membuat siswa terampil mengerjakan soal-soal sendiri dan belajar mengatasi masalah, memberikan suasana yang kreatif dan menyenangkan serta menumbuhkan jiwa kompetisi yang tinggi antar kelompok, sehingga setiap anggota kelompok bekerjasama dan berusaha untuk memenangkan permainan dengan mendapatkan poin tertinggi. Peningkatan hasil belajar kognitif siswa dalam penggunaan media Tournament Question Cards menunjukan hasil yang baik, hal ini terlihat dari peningkatan hasil belajar kognitif siswa yang mencapai nilai di atas standar KKM berjumlah 34 siswa. Hal ini sesuai dengan hasil penelitian yang dilakukan sebelumnya bahwa penerapan media Question Cards dapat meningkatkan hasil belajar siswa dalam proses pembelajarannya.[11]

Pada kelas eksperimen II penggunaan media Chemopoly Game memiliki kelebihan yaitu membuat suasana kelas lebih menyenangkan dan menghilangkan kejenuhan siswa dalam proses pembelajaran sehingga penggunaan media mampu meningkatkan hasil belajar siswa terlihat dari peningkatan hasil belajar kognitif siswa yang mencapai nilai di atas standar KKM berjumlah 25 siswa. Namun Penggunaan media Chemopoly Game juga memiliki kekurangan yaitu fokus siswa menjadi teralihkan pada unsur permainannya saja, bukan pada soal-soal yang dikemas di dalam media tersebut. Hal ini dikarenakan Chemopoly Game merupakan adopsi dari permainan monopoli sehingga fokus siswa menjadi terbagi-bagi dan kesempatan untuk mendapatkan kartu bank soal juga sangat kecil sehingga siswa menjadi tidak tertarik untuk mengumpulkan kartu bank soal melainkan siswa lebih tertarik untuk mengumpulkan uang sebanyak-banyaknya. Meskipun di 
akhir permainan setiap kelompok diperbolehkan menukarkan uang yang telah dikumpulkan dengan kartu bank soal, tetapi masih ada kelompok yang tidak menukarkan paling banyak bukan dari banyaknya poin soal yang didapat. Selain itu, adanya anggapan siswa bahwa yang memenangkan permainan adalah kelompok yang mengumpulkan uang terlibat aktif dalam proses pembelajarannya tetapi masih ada siswa yang belum sepenuhnya menangkap konsep yang dikemas dalam media tersebut. Hal ini dikarenakan pada saat diskusi hanya sebagian anggota saja yang mengerjakan soal tersebut sehingga anggota lainnya hanya sebagai pencatat dan pendengar saja. Berdasarkan mengerjakan soal-soal yang ada di bank soal dan lembar LKS, hal ini dikarenakan kartu bank soal yang didapat hanya sedikit jadi tidak semua anggota mendapatkan kesempatan untuk hasil dan penjelasan di atas dapat disimpulkan bahwa hasil belajar kognitif siswa yang menggunakan media Tournament Question Cards lebih baik jika dibandingkan dengan media Chemopoly Game. Hal ini dilihat darin nilai $\mathrm{t}_{\mathrm{Hitung}}$ yang diperoleh 2,62 lebih besar dibandingkan dengan nilai $\mathrm{t}_{\text {Tabel }}$ yaitu 2,38.

\section{KESIMPULAN}

Hasil belajar siswa yang menggunakan media Chemopoly Game diketahui memiliki nilai rata-rata pretest sebesar 28,72 dan nilai rata-rata postest sebesar 79,38 dengan selisih nilai rata-rata pretest dan postest sebesar 50,67.

Hasil belajar siswa yang menggunakan media Tournament Question Cards diketahui memiliki nilai rata-rata pretest sebesar 28,24 dan nilai rata-rata postest sebesar 85,59 dengan selisih nilai rata-rata pretest dan postest sebesar 57,35 .

Terdapat perbedaan yang signifikan antara hasil belajar siswa dalam pembelajaran kooperatif tipe Student Teams Achievement Divisions (STAD) dengan menggunakan media Chemopoly Game dan Tournament Question Cards pada pokok bahasan hukum dasar kimia di kelas X SMA Negeri 2 Kota Bengkulu. Hal ini dilihat dari nilai $t_{\text {Hitung }}>t_{\text {Tabel }}$, di mana nilai $t_{\text {Hitung }}$ adalah 2,62 sedangkan $\mathrm{t}_{\text {Tabel }}$ adalah 2,38.

\section{SARAN}

Dalam penggunaan media Chemopoly Game maupun media Tournament Question Cards sangat dibutuhkan perencanaan dan pengelolaan kelas yang baik agar suasana kelas tetap kondusif dan pembelajaran dapat berlansung efektif.

Pada saat pembelajaran dengan media Chemopoly Game sebaiknya aturan permainan lebih diperjelas agar tidak terjadi kesalahan dalam proses pembelajarannya.

\section{UCAPAN TERIMAKASIH}

Terima kasih kepada Bapak Dr. Bihanudin, S.Pd., M.Pd selaku Kepala Sekolah SMA Negeri 2 Kota Bengkulu yang telah memberikan izin penelitian, dan Ibu Sri Meinarti, S.Pd selaku guru mata pelajaran kimia SMA Negeri 2 Kota Bengkulu yang senantiasa membimbing serta membantu kelancaran penelitian, serta semua pihak yang telah banyak membantu dalam penyelesaian penelitian ini.

\section{DAFTAR PUSTAKA}

[1] Perdana, Utomo dan Yamtina Sri. 2014. Upaya Peningkatan Minat Dan Prestasi Belajar Materi Hidrokarbon Melalui Penerapan Model Pembelajaran Kooperatif Tipe Student Team Achievement Division (STAD) Berbantuan Kartu Soal Pada Siswa Kelas X Semester Genap SMAN 8 Surakarta Tahun Pelajaran 2012/2013. Jurnal Pendidikan Kimia. 3(1). ISSN : 2337-9995.

[2] Fajri, Martini dan Nugroho. 2014. Upaya Peningkatan Proses Dan Hasil Kimia Materi Koloid Melalui Pembelajaran Kooperatif Tipe TGT (Teams Games Tournament) Dilengkapi Dengan Teka-Teki Silang Bagi Siswa Kelas XI IPA 4 SMA Negeri 2 Boyolali Pada Semester Genap Tahun Ajaran 2011/2012. Jurnal Pendidikan Kimia. 1(1). ISSN : 2337-9995.

[3] Nur, Maridi dan Harlita. 2015. Pengaruh Pembelajaran Kooperatif Student Team Achievement Divisions (STAD) Disertai LKS Terhadap Hasil Belajar Biologi Siswa Kelas VII SMP Negeri 21 Surakarta. Bio-Pedagogi. 4(2) . ISSN : 2252-6897.

[4] Octavianti, Ashadi dan Rejeki Tri. 2014. Studi Komparasi Model Pembelajaran Kooperatif Metode STAD (Student Team Achievement Division) Berbantuan Macromedia Flash Pada Pembelajaran Materi Senyawa Hidrokarbon. Jurnal Pendidikan Kimia. 3(1). ISSN : 2337-9995

[5] Arsyad, Azhar. 2013. Media Pembelajaran. Jakarta : PT Raja Grafindo Persada. ISBN : 978-979-79513-2.

[6] Rohmah, Iftitahur. 2014. Pengaruh Model Pembelajaran Teams Assisted Individual Dengan Proyek Teka-Teki Silang dan Dilengkapi Lembar Kerja Siswa Terhadap Prestasi Belajar Pada Materi Koloid Siswa Kelas Xi SMA Negeri 3 Surakarta Semester Genap Tahun Ajaran 2013/2014. Jurnal Pendidikan Kimia. 3(3) . ISSN : 2337-9995.

[7] Taqwima, Ashadi dan Utami Budi. 2013. Studi Komparasi Pembelajaran Kooperatif Metode Teams Games Tournament (TGT) Menggunakan Media Chemopoly Game Dan Chem-Cards Game Pada Materi Pokok Sistem Koloid Kelas Xi Semester Genap SMA Negeri 1 Surakarta Tahun Pelajaran 
2012/2013. Jurnal Pendidikan Kimia. 2(4) . ISSN : 2337-9995.

[8] Susanto, Raharjo dan Muji. 2012. Permainan Monopoli Sebagai Media Pembelajaran Sub Materi Sel Pada Siswa Sma Kelas XI IPA. BioEdu. 1(1).

[9] Ifadloh, Santoso dan Supardi. 2012. Metode Diskusi Dengan Pendekatan Science, Environment, Technology, Society Dan Media Question Card. Unnes Science Education Journal. 1(2) . ISSN : 2252-6617

[10] Ardani, N,P,M, Putra, I.K.A, Rini Kristiantari, M.G, 2014. Pengaruh Model Kooperatif TGT Berbantuan Media Question Card Terhadap Hasil Belajar IPS Siswa Kelas V. Jurnal Mimbar PGSD. Vol 2 No 1
[11] Sari, Armynda dan Supardi. 2013. Pengaruh Model Team Games Tournament Media TournamentQuestion Cards Terhadap Hasil Belajar Siswa Pada Materi Hidrokarbon. Jurnal Inovasi Pendidikan Kimia.7(2).

Penulisan Sitasi Artikel ini ialah :

Viani, D.S, , Bahar, A. , Elvinawati. 2017, Perbandingan Hasil Belajar Siswa Menggunakan Media Chemopoly Game Dan Tournament Question Cards, Alotrop, 1(1):55-59. 